\title{
Correction to: $\mathrm{Fe}_{3} \mathrm{O}_{4} @ \mathrm{SiO}_{2}$-PTMS-Guanidine-SA nanoparticles as an effective and reusable catalyst for the synthesis of $\mathrm{N}$-substituted pyrroles
}

\author{
Hedieh Rostami ${ }^{1}$. Lotfi Shiri ${ }^{1}$
}

Published online: 7 February 2020

(c) Iranian Chemical Society 2020

\section{Correction to: Journal of the Iranian Chemical Society https://doi.org/10.1007/s13738-020-01857-7}

The article " $\mathrm{Fe}_{3} \mathrm{O}_{4} @ \mathrm{SiO}_{2}$-PTMS-Guanidine-SA nanoparticles as an effective and reusable catalyst for the synthesis of $N$-substituted pyrroles", written by Hedieh Rostami - Lotfi Shiri, was originally published electronically on the publisher's Internet portal (currently SpringerLink) on 21 January 2020 with open access. With the author(s)' decision to step back from Open Choice, the copyright of the article changed on February 2020 to $\odot$ Iranian Chemical Society 2020, part of Springer Nature 2020, and the article is forthwith distributed under the terms of copyright.

The original article can be found online at https://doi.org/10.1007/ s13738-020-01857-7.

Lotfi Shiri

1shiri47@gmail.com; 1.shiri@ilam.ac.ir

1 Department of Chemistry, Faculty of Basic Sciences, Ilam University, P.O. Box 69315-516, Ilam, Iran 